This document is the accepted manuscript version of the following article:

Kääb, A., Leinss, S., Gilbert, A., Bühler, Y., Gascoin, S., Evans, S. G., ... Yao, T. (2018). Massive collapse of two glaciers in western Tibet in 2016 after surge-7ike instability. Nature Geoscience, 11(2), 114-120.

https://doi .org/10.1038/s41561-017-0039-7

\title{
Massive collapse of two glaciers in western Tibet in 2016 after surge-like instability
}

Andreas Kääb, Silvan Leinss, Adrien Gilbert, Yves Bühler, Simon Gascoin, Stephen G. Evans, Perry Bartelt, Etienne Berthier, Fanny Brun, Wei-An Chao, Daniel Farinotti, Florent Gimbert, Wanqin Guo, Christian Huggel, Jeffrey S. Kargel, Gregory Leonard, Lide Tian, Désirée Treichler, and Tandong Yao. 


\section{Affiliations}

Department of Geosciences, University of Oslo, 0316 Oslo, Norway

Andreas Kääb, Adrien Gilbert, Desirée Treichler

Institute of Environmental Engineering, ETH Zurich, 8093 Zurich, Switzerland

Silvan Leinss

WSL Institute for Snow and Avalanche Research SLF, 7260 Davos Dorf, Switzerland

Yves Bühler, Perry Bartelt

CESBIO, Université de Toulouse, CNES, CNRS, IRD, UPS, Toulouse, France

Simon Gascoin

Department of Earth and Environmental Sciences, University of Waterloo, Waterloo, ON, CANADA N2L 3G1

Stephen G. Evans

LEGOS, Université de Toulouse, CNES, CNRS, IRD, UPS, Toulouse, France

Etienne Berthier, Fanny Brun

Univ. Grenoble Alpes, CNRS, IRD, Grenoble INP, IGE, 38000 Grenoble, France

Fanny Brun, Florent Gimbert

Department of Civil Engineering, National Chiao Tung University, Hsinchu 30010, Taiwan,

R.O.C

Wei-An Chao

Laboratory of Hydraulics, Hydrology and Glaciology, ETH Zurich, 8093 Zurich, Switzerland;

Swiss Federal Institute for Forest, Snow and Landscape Research (WSL), 8903 Birmensdorf, Switzerland

Daniel Farinotti

Northwest Institute of Eco-Environment and Resources, Chinese Academy of Sciences, Lanzhou, Gansu 730000, China

Wanqin Guo

Department of Geography, University of Zurich, 8057 Zurich, Switzerland

Christian Huggel

Department of Hydrology and Atmospheric Sciences, University of Arizona, and Planetary Science Institute, Tucson AZ 85721, USA

Jeffrey S. Kargel

Lunar and Planetary Laboratory, University of Arizona, Tucson AZ 85721, USA

Gregory Leonard

Institute of Tibetan Research, Chinese Academy of Sciences, Beijing 100101, China

Lide Tian, and Tandong Yao 
Surges and glacier avalanches are expressions of glacier instability, and among the most dramatic phenomena in the mountain cryosphere. To date, the catastrophic collapse of a glacier, combining the large volume of surges and mobility of ice-avalanches, has only been reported for the $2002130 \mathrm{Mm}^{3}$ detachment of Kolka Glacier (Caucasus Mountains), which has been considered a globally singular event. Here, we report on the similar detachment of the entire lower parts of two adjacent glaciers in western Tibet in July and September 2016, leading to an unprecedented pair of giant low-angle ice avalanches with volumes of $68 \pm 2$ and $83 \pm 2 \mathrm{Mm}^{3}$. Based on satellite remote-sensing, numerical modelling and field investigations we find that the twin collapses were caused by climate and weather-driven external forcing, acting on specific polythermal and soft-bed glacier properties. These factors converged to produce surge-like enhancement of driving stresses and massively reduced basal friction connected to subglacial water and fine-grained bed lithology, to eventually exceed collapse thresholds in resisting forces of the tongues frozen to their bed. Our findings show that large catastrophic instabilities of low-angle glaciers can happen under rare circumstances without historical precedence.

Sudden, gravity-driven mass failures of glaciers have been observed over a wide range of magnitudes, from ice falls at steep glacier fronts to large ice avalanches when hanging glaciers, typically steeper than $30^{\circ}$, detach ${ }^{1,2}$. Impacts are mostly within a couple of kilometres, except when the ice transforms to a highly mobile mass flow through ingestion and production of melt water and incorporation of sediments ${ }^{3,4}$. Pre-failure conditions and triggering factors typically include topographic, atmospheric and ice-thermal conditions ${ }^{1,2}$, underlying bedrock instabilities or seismic events ${ }^{3,5}$.

Glacier surges constitute a second process of glacier instability and refer to events lasting weeks to a few years with abnormally high flow speeds of up to tens to hundreds of metres per day over large glacier parts ${ }^{6-10}$. Clusters of surge-type glaciers are found in mountain regions around the world, including the Tibetan Plateau ${ }^{7,9,11}$. Processes involved in the lowering of basal friction required for surging include abnormally high water pressure ${ }^{8,11,12}$, change in the thermal regime end $11,13,14$ and complex responses of sub-glacial till rheology to increasing shear stress and water input ${ }^{6,8,11,12,15-17}$.

A third type of glacier instability involves the detachment of large parts of low-angle valley glaciers. This process has only been documented for the 2002 Kolka Glacier event (Kazbek massif, Caucasus), when a $130 \mathrm{Mm}^{3}$ ice/rock avalanche travelled $18 \mathrm{~km}$ down-valley and claimed 120 lives $^{18-20}$. The massive 2016 glacier collapses in Tibet $^{21}$ have changed this picture and opened up critical questions about the causes of the detachments and the potential for similar events to occur elsewhere. Here, we describe the Tibet twin events and reconstruct the evolution of the collapsed glaciers since the 1960s, based on remote sensing and mass-balance modelling. For more recent years we analyse glacier dynamics and model the thermal conditions to infer on the glacier's stress and frictional regime. Finally, we discuss the influences of melt and precipitation, bed lithology, and glacier geometry on the collapses. 


\section{Glacier collapses transform into giant high-speed avalanches}

On 17 July 2016, 11:15am Beijing time, a massive volume of glacier ice detached from the lower part $(5,800-5,190 \mathrm{~m}$ a.s.l.) of an unnamed glacier in the Aru Range (Rutok County, China) in the western Tibetan Plateau (termed Aru-1 for both glacier and collapse; Figs. 1,2). The fragmented ice mass ran out $6 \mathrm{~km}$ beyond the glacier terminus, killing nine herders and hundreds of their animals, and reached the Aru Co lake ${ }^{21}(\sim 4,970 \mathrm{~m}$ a.s.l.; Fig. 1). The avalanche horizontal distance of $8.2 \mathrm{~km}$ and its vertical path of $800 \mathrm{~m}$ yield a surprisingly low angle of reach of only 5$6^{\circ}$ (mobility index fahrböschung ${ }^{22}$ ), indicating very low basal friction in the movement. The ice debris covered $8-9 \mathrm{~km}^{2}$ and using pre/post-collapse differencing of digital elevation models (DEMs), a volume of the detached glacier part of $68 \pm 2 \mathrm{Mm}^{3}$ was calculated (Fig. 2; Methods). The avalanche generated an impact wave, which inundated the opposite shore of Aru Co over a shoreline distance of $10 \mathrm{~km}$, extending up to $240 \mathrm{~m}$ inland and $9 \mathrm{~m}$ above lake level (Methods and Supplementary Information S11).

In a dramatic turn of events, on 21 September 2016, a second glacier (Aru-2) detached just $2.6 \mathrm{~km}$ south of the July event. The detachment occurred at 5,800-5,240m a.s.l. in two main flows at $\sim 5 \mathrm{am}$ and 11:20am Beijing time (Figs. 1,2). Similar to the July event the glacier mass fragmented and transformed into a mass flow that ran out $5 \mathrm{~km}$ beyond the glacier terminus, reaching $4,965 \mathrm{~m}$ a.s.l. Over a horizontal distance of $7.2 \mathrm{~km}$ the vertical height of the path was $830 \mathrm{~m}$, giving a similarly low fahrböschung of $6-7^{\circ}$. The glacier debris in the second collapse covered $6-7 \mathrm{~km}^{2}$ with a detached glacier volume of $83 \pm 2 \mathrm{Mm}^{3}$ (Fig. 2).

Eye witness reports, the geomorphology of the avalanche paths and deposits, and observations of seismic waveforms generated by the mass movements all suggest the events were sudden and fast (2-3min duration, $30-40 \mathrm{~m} \mathrm{~s}^{-1}$ mean speed; Supplementary Information S10). Consistent with the low basal friction estimated from the avalanche paths, the analysis of the three dimensional forces inverted from the glacier avalanche seismic signals ${ }^{23}$ also reveals exceptionally low basal friction-coefficients of $0.11 \pm 0.07$ and $0.14 \pm 0.05$ for Aru- 1 and 2, respectively (ratio between frictional and normal force; Supplementary Information S10). These values are significantly smaller than values on the order of 0.2-0.6 previously found for landslides. Using different numerical avalanche flow model $\mathrm{s}^{24,25}$ we find average flow speeds of $\sim 20 \mathrm{~m} \mathrm{~s}^{-1}$, peaking at $70-90 \mathrm{~m} \mathrm{~s}^{-1}$ in the gorge sections of the paths. High avalanche speeds are also indicated by the presence of undestroyed grassy vegetation on the lee side of hills in the Aru-1 avalanche path suggesting that the fast-moving mass had partially jumped over it ${ }^{19}$ (Supplementary Information S1). The high speeds for both Aru avalanches suggest processes of ice liquefaction from frictional heating during the collapse and flow ${ }^{26}$. From simple energyconservation up to $2.3 \%$ of the ice could have liquefied if all potential energy was consumed, with the generated water likely concentrated at the bed of the flow.

Prior to the Aru-2 collapse, crevasses very similar to the ones preceding the Aru-1 event were detected on satellite imagery (Fig. 3f), the potential avalanche run-out geometry and general deposition pattern were modelled with the parameters inferred from the Aru- 1 simulation, and an alert was issued to Chinese authorities. 


\section{Climate and glacier changes 1961-2016}

We investigate recent climate and meteorological records in the Aru region to identify possible pre-conditions and triggers for the two glacier collapses. The Shiquanhe meteorological station (Fig. 1), providing the closest long-term record, reveals strong warming of $1.7 \pm 0.5^{\circ} \mathrm{C}$ since 1965 (Supplementary Information S3), in line with reductions in glacier length in the western Tibetan Plateau ${ }^{27,28}$. Precipitation at Shiquanhe does not show a long-term trend, but exceptionally large precipitation sums occurred in 2013 and 2015, and in 2016 at the Nagri station (established in 2010).

Using Corona satellite imagery over the period 1961-1980, Landsat from 1972 on, and highresolution optical and radar satellites from 2011 to date, we find that the glaciers in the Aru Range retreated from the 1970s on; Aru- 1 and Aru- 2 glaciers by 520 and $460 \pm 15 \mathrm{~m}$ between 1970 and 2015 or 2016, respectively. In contrast to this frontal retreat, analysis of DEMs from SRTM-X (2000), TanDEM-X (2011-2016), and the Advanced Spaceborne Thermal Emission and Reflection Radiometer ${ }^{29}$ (ASTER; 2000-2015; Methods), together with ICESat laser altimetry ${ }^{30}$ (2003-2008) show that glaciers in the wider Aru region are part of the Karakoram, Kulun Shan and Eastern Pamir anomaly $y^{29,30}$ and experienced a slight thickness increase of between $0.20 \pm 0.16$ and $0.28 \pm 0.15 \mathrm{~m} \mathrm{yr}^{-1}$ water equivalent (w.e.) since the early 2000s (ASTER and ICESat, respectively; Fig. 4). Simultaneous high-elevation thickening and low-elevation thinning and terminus retreat causes steepening of the glacier surface and is generally untypical. However, for non-surge-type glaciers it has been observed when both temperature and snowfall increase together ${ }^{31}$ causing increased ice melt and accumulation. Specifically, non-surging glaciers in the Aru region thickened by up to $0.40 \pm 0.15 \mathrm{~m} \mathrm{yr}^{-1}$ above around $5,650 \mathrm{~m}$ a.s.l. and thinned up to $1.20 \pm 0.15 \mathrm{~m} \mathrm{yr}^{-1}$ below that elevation (Fig. 5a). For at least 5 of 16 glaciers in the range north of the Aru Range this overall climate-driven pattern of surface elevation changes was interrupted by surge-type mass redistributions over 2000-2016 (Supplementary Information S7).

Despite regional warming, mass-balance modelling of the Aru glaciers (Fig. 4, Methods and Supplementary Information S3) confirms positive mass balances between 1995 and 2008, and steepening of the mass-balance gradient. We attribute this to a precipitation increase since the mid-1990s $\mathrm{s}^{32,33}$ captured by the ERA-interim reanalysis that drives our model. This precipitation increase is confirmed by wide-spread growth of the region's endorheic lakes during the same period $^{34}$.

Searching the Corona (from 1961) and Landsat (from 1972) archives we find no indication of earlier glacier collapses in the Aru Range and its wider region (radius of ca. $300 \mathrm{~km}$ ). We note though that early Corona images and 2015/2016 satellite data for the two Aru glaciers and some of their close neighbours show similar strong crevassing and bulged tongues, i.e., features commonly presaging surge-like instabilities or rapid advance (Supplementary Information S1).

\section{Pre-collapse mass redistribution within polythermal glaciers}

Patterns of glacier-surface elevation changes in the immediate pre-collapse period (2011-2015) are measured from repeat TanDEM-X DEMs and optical satellite stereo DEMs (Fig. 5b,c; 
Methods and Supplementary Information S7). At least as early as 2011 and until 2014, the sections above the eventual detachment zones of both Aru glaciers at $\sim 5,800 \mathrm{~m}$ subsided. Simultaneously, glacier sections $\sim 5,800-5,400 \mathrm{~m}$ a.s.I. bulged upwards. Combined with thickness loss at the termini $\sim 5,400-5,200 \mathrm{~m}$ a.s.l., the bulging led to steepening by $5-6^{\circ}$ at its front, and thus to locally increasing driving stresses. The elevation change rates derived for 2011-2014 indicate that a down-glacier mass transfer had begun already 2003 $\pm 3 y r$ (Supplementary Information S7). However, this internal mass movement did not cause surging of Aru-1 before mid-2015 and only $200 \pm 15 \mathrm{~m}$ terminus advance up to collapse, whilst no advance was detected for Aru-2 at all (Fig. 3). These observations indicate strong resistive forces to sliding at the glacier termini, suggesting they were frozen to their beds ${ }^{14}$.

Image offset-tracking reveals that the Aru-1 medial bulge was associated with increased ice velocities, from $0.18 \pm 0.03 \mathrm{~m} \mathrm{~d}^{-1}$ in late-2013, to $0.50 \pm 0.04 \mathrm{~m} \mathrm{~d}^{-1}$ in spring 2016 (Supplementary Information S8). These are 3-10 times higher flow speeds compared to the modelled steadystate flow of $0.05 \mathrm{~m} \mathrm{~d}^{-1}$ (Methods). For the Aru-2 glacier we find unchanged average central speeds in the medial bulge of $0.12 \pm 0.03 \mathrm{~m} \mathrm{~d}^{-1}$ between July 2013 and April 2016.

Strongly enhanced crevassing developed on both glaciers in the weeks to months before the detachments (Fig. 3). Crevassing was particularly evident along the lateral margins and across the glaciers at an elevation of $\sim 5,800 \mathrm{~m}$ a.s.l., indicating increased displacement where the glaciers later detached. On Aru-1, cracks across the entire glacier had already evolved in September 2015 (Supplementary Information S1). Fast-developing crevasses on Aru-2 were discovered in satellite images before its collapse.

The high initial acceleration of the avalanches, the pattern of glacier surface height-changes, thermo-mechanical modelling of the glaciers outlined below, and the crevasse formation indicate that enhanced basal sliding first occurred in the central parts of the glaciers. The presence of large amounts of water is also suggested by a mudflow-like fan of basal fines originating at around 5,550m a.s.l. from crevasses, which is observed on satellite images of Aru1 from two days before its collapse (Fig. 3). No such observation was made for Aru- 2 .

Thermo-mechanical modelling (Methods) indicates that the ice-bed interface was probably temperate (thawed) in the central part of the glaciers but cold (frozen) in the remaining zones (Fig. 6) suggesting a polythermal structure for the Aru glaciers. The model-indicated thermal patterns are supported by the late (Aru-1) or missing (Aru-2) advances of the fronts, significant ice masses sticking at the glacier margins after detachment (Fig. 1), and the location of the Aru range within a semi-arid permafrost region ${ }^{35}$. The polythermal glacier structure created conditions for (i) margins and fronts of the glacier tongues to be frozen to the underlying bed, (ii) infiltrating meltwater to reach the glacier bed at the top of the detachment zones, (iii) the retention of this water upslope of the cold-based plugs creating the precursory friction decrease within the medial bulges ${ }^{17}$, and (iv) the development of a progressively steepening geometry upstream of the cold-based fronts. Critically, the cold-based front prevented the glacier geometry to adapt quickly enough to the reduction in friction, as would be the case during typical surges. The accumulation of water at the glacier bed through ingress of rainfall 
and in particular summer melt was probably accelerated after 2010 when the sum of both contributions increased by 50\% (Supplementary Information S3,4).

\section{Causes and implications}

No earthquake seismicity was associated with the initiation of either event (Methods). Global Precipitation Measurement Integrated Multi-Satellite Retrievals (GPM IMERG) and the meteorological stations in the region indicate significant amounts of precipitation throughout the summer of 2016 of up to $200 \mathrm{~mm}$ or more in total. For the two days immediately preceding the Aru-1 collapse $10-25 \mathrm{~mm}$ rainfall was observed (Supplementary Information S6). Optical satellite images reveal considerable rates of snow-cover reduction in the weeks before the collapse. Very low backscatter in Sentinel-1 radar data from 1 July until 31 August 2016 indicates continued melting conditions up to the mountain tops of the Aru Range ( 6,100m a.s.I.; Supplementary Information S4). No similar strong precipitation is observed for the days immediately preceding the Aru- 2 event, although several rainfall events occurred during the weeks prior to collapse. Hence, at least for Aru-1, unusually high liquid water input from melting and precipitation (highest positive degree-day sum since 1979 found for 2016; Supplementary Information S3) increased the water content in the glacier system, and thus puts it among the possible triggering factors for the collapse.

An important factor relates to the deformable bed ${ }^{6,8,15,16,36,37}$ of the Aru glaciers, linked to the fine-grained sandstone and siltstone lithology underneath the collapsed Aru glaciers (Methods). We suggest that upon commencement of basal thaw and sliding the till formed from these lithologies, combined with the high water input, may have locally formed basal slurries with low shear strength under high pore-fluid pressure ${ }^{38}$, and possibly have destroyed any subglacial drainage system ${ }^{17}$. The limited strength of the till in those areas would have induced a rheology prone to trigger instabilities ${ }^{39,40}$.

The curved shape in plan-geometry of the two glacier tongues might also have influenced their stability by causing lateral resistance ${ }^{8}$. This is indicated by strong crevassing (Fig. 3) and maximum flow speeds at the northern, left-lateral glacier margins (Supplementary Information S8). We also note that the surface slopes of $12-13^{\circ}$ (bed slopes $9-10^{\circ}$ ) of the detached avalanche sources rank rather high for surge-type glacier tongues, thus exerting high driving stresses $^{8}$.

In sum, the foregoing shows that there is no evidence for a single trigger for the twin collapses. The surge-like behaviour, climate-driven glacier surface steepening, polythermal glacier structure, their geometry and slope, and liquid water from melt and rain during summer 2016 are all factors found for a number of other glaciers both on the Tibetan Plateau and elsewhere. We propose therefore that a transient convergence of factors acting at different spatial and temporal scales caused the Aru collapses. A polythermal glacier regime, glacier morphology and bedrock lithology represent important basic conditions. Over timescales of 15-20 years, the simultaneous increase in temperature and precipitation has acted on the glacier geometry and basal friction by respectively increasing the slope and enhancing liquid water input to the glacier bed, and possibly expanding the area of thawed conditions. The presence of cold-based 
fronts and margins prevented the glaciers from adjusting their geometries to changed driving stresses and frictional conditions. This continuously increased the stresses on the frozen terminus and margins, until reaching a critical point for which the resisting forces were eventually overcome and the collapses occurred. The sustained exceptional low frictions over large parts of the glaciers make the events unique and are probably associated with a particular response of the fine-grained basal till to large amounts of liquid water ${ }^{6,8,17,41}$. The final trigger is thought to be linked to short-term variation in the subglacial hydrological system induced by the unusually high water input from melt and rain in the summer of 2016. Hydrothermodynamic feedback ${ }^{42}$ potentially played a role as well-a mechanism by which water reaching the glacier bed through crevasses increases basal sliding, strain, and associated fracturing through a combination of thermal and dynamic changes, thus facilitating additional water input and modifying subglacial drainage ${ }^{43}$.

Some similarities exist between the 2016 Aru events and the 2002 Kolka Glacier collapse including volume, glacier and avalanche slopes, and avalanche speed. In the days before detachment ${ }^{18-20}$, Kolka Glacier showed signs of destabilization including heavy crevassing and bulging, and unusual hydrological conditions ${ }^{43}$ such as supraglacial ponds. This glacier surged in $1969 / 70^{19}$ and had a slope similar to the two Aru glaciers ${ }^{18}$. The Kolka/Kazbek area is known for its fine-grained rocks and sediments of volcanic origin ${ }^{44}$ causing a variety of violent mass movements ${ }^{45}$, and putting forward the possible role of lithology in the rapid and sustained reduction of basal friction in the three events. Unusually high geothermal heat-fluxes underneath the Kolka ${ }^{44}$ and Aru glaciers (Methods) are uncertain but cannot be excluded. In contrast to the Aru glaciers, however, Kolka Glacier must have been temperate throughout. Over some weeks before the event, moreover, heavy rock/ice-fall activity deposited several $\mathrm{Mm}^{3}$ of material on the glacier ${ }^{18-20}$. The Kolka and Aru cases together suggest thus two possibilities to reach critical glacier geometry and associated increase in driving stresses, i.e., additional loading from surrounding mass movements (Kolka) or glacier steepening (Aru).

In conclusion, the Aru twin glacier collapses have allowed us to recognize a new form of glacier instability - the catastrophic collapse of large parts (here $25-30 \%$ by area, and up to $40 \%$ by volume) of an entire valley glacier. These collapses seem possible through a rare but not unique array of factors that coalesce to an anomalous increase in driving stresses, and rapid and sustained reduction of basal friction. It is spectacular and completely unprecedented that such combined exceedance of stability thresholds, highly unlikely for one glacier alone, occurred for two neighbour glaciers within just two months. Rock-mechanical or hydrologic/hydraulic collateral effects through which the Aru-1 collapse could have preconditioned or triggered Aru2 appear implausible, highlighting the role of common external forcing by climate and weather in synchronizing the two collapses. Our findings shed new light on the occurrence of glacier surge-related instabilities; several documented glacier instabilities ${ }^{46-50}$ should be revisited to clarify their relation to the processes of glacier collapse suggested here. The transient nature of some of the factors involved in the Aru and Kolka collapses, and the range of conditions and thresholds suggested by the differences between them, imply that such events can happen without historical precedence. Once the Aru avalanche deposits have melted, their geomorphic and lithologic imprint should be investigated and the wider region be searched for signs of 
potential previous glacier collapses. Our analyses show that under specific circumstances climate variability and change have a critical potential to contribute to large-scale glacier instability by changing glacier geometry, thermal conditions, and liquid water content. Although long-term prediction of similar events seems beyond reach for the time being, the pre-event observations and simulations of the Aru-2 collapse demonstrate that available, state-of-the-art ground-based and satellite monitoring, and modelling capabilities allow for early-warnings to be issued even in very remote regions. Harnessing these capabilities would allow for scientific advances to benefit also the most remote communities. 


\section{Corresponding Author}

Correspondence to Andreas Kääb (kaeaeb@geo.uio.no)

\section{Acknowledgements}

We are grateful to the satellite data providers: Planet for their cubesat data via Planet's Ambassadors Program, Copernicus/EU/ESA for Sentinel-1 and 2, CNES for Pleiades, USGS for Landsat 8, DLR for the TerraSAR-X and TanDEM-X, and JPL and METI for ASTER. A.K. thanks Jane Qiu for initial information about the first event and discussions. A.K., A.G. and D.T. acknowledge the Univ. Oslo EarthFlows initiative and funding from the European Research Council under the European Union's Seventh Framework Programme (FP/2007-2013)/ERC grant agreement no. 320816, and A.K. in addition the ESA projects Glaciers_cci (4000109873/14/I-NB) and DUE GlobPermafrost (4000116196/15/IN-B). S.G., E.B., F.B. acknowledge support from the French Space Agency (CNES) and the Programme National de Télédétection Spatiale grant PNTS-201601. J.K. acknowledges support from the ASTER science team. This study was coordinated within the IACS and IPA Standing Group on Glacier and Permafrost Hazards in Mountains (GAPHAZ).

\section{Author Contribution}

All authors conceived the study, and collected, processed and analysed data. A.K., S.L., S.G., E.B., F.B., J.K., G.L., D.T. performed remote sensing analyses, A.G. mass balance and thermodynamical glacier modelling, Y.B., P.B. and S.G.E. avalanche modelling, W.C. and F.G. seismic data analysis and modelling, W.G., L.T., T.Y., A.G. field surveys and reconnaissance, and S.G.E., D.F., C.H. further analyses and interpretations. All authors contributed to writing the paper.

\section{Competing interests}

The authors declare no competing financial interests. 


\section{Figures}
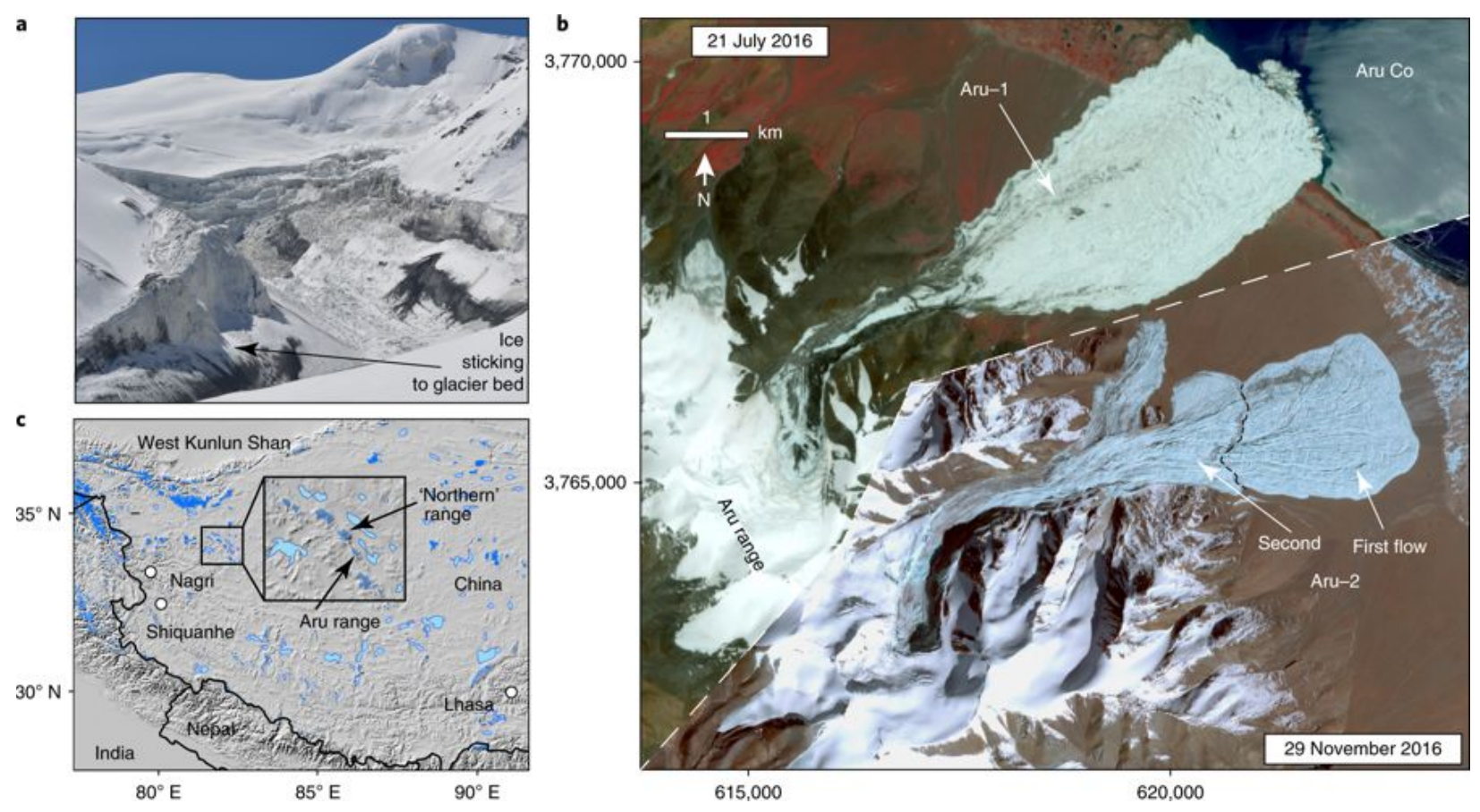

Figure 1: Satellite and terrestrial images of the Aru glacier collapses.

a, Photo of upper Aru-2 detachment zone (4 October 2016). b, Mosaic of Sentinel-2 image of Aru-1 collapse (21 July 2016) and Planet image of Aru-2 collapse (29 November 2016), image centre approximately $34.03^{\circ} \mathrm{N} / 82.28^{\circ} \mathrm{E}$. c, Overview of study region with meteorological stations used. 

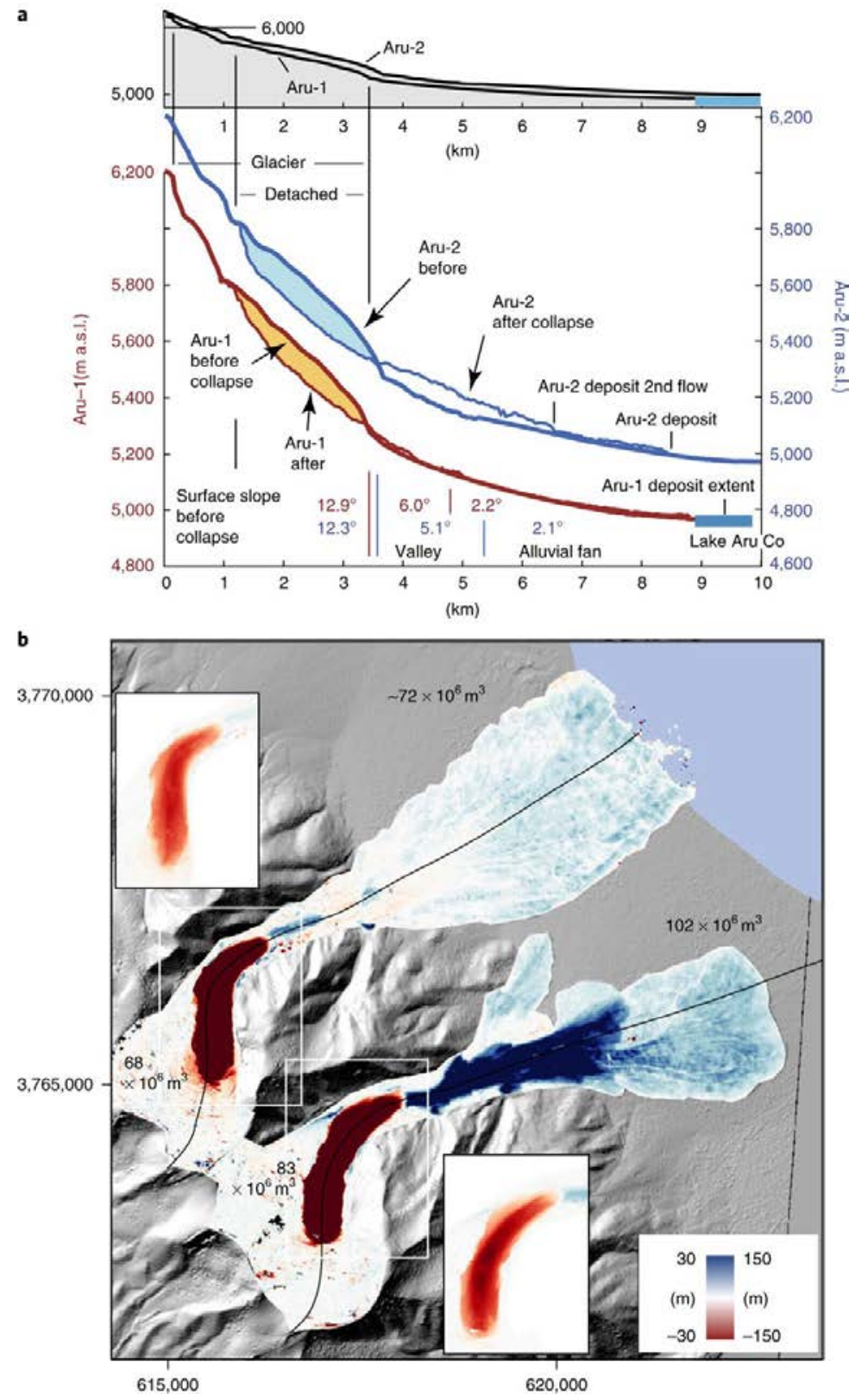

Figure 2: Geometry and thicknesses of the Aru collapses and avalanches.

a, Longitudinal profiles over the collapses and avalanche deposits without and with vertical exaggeration. Profile location in panel b. b, Elevation changes between 25 November 2015 (SPOT7, outside glaciers merged with TanDEM-X) and 1 October 2016 (Pléiades). The collapse source zones are given in two colour scales $( \pm 30 \mathrm{~m}$, main figure; $\pm 150 \mathrm{~m}$, insets). Note the distinct steps of deposit thickness between the upper and lower parts of the Aru-2 mass-flow deposits and within the lower part. Numbers in the panel indicate source and deposit volumes. 

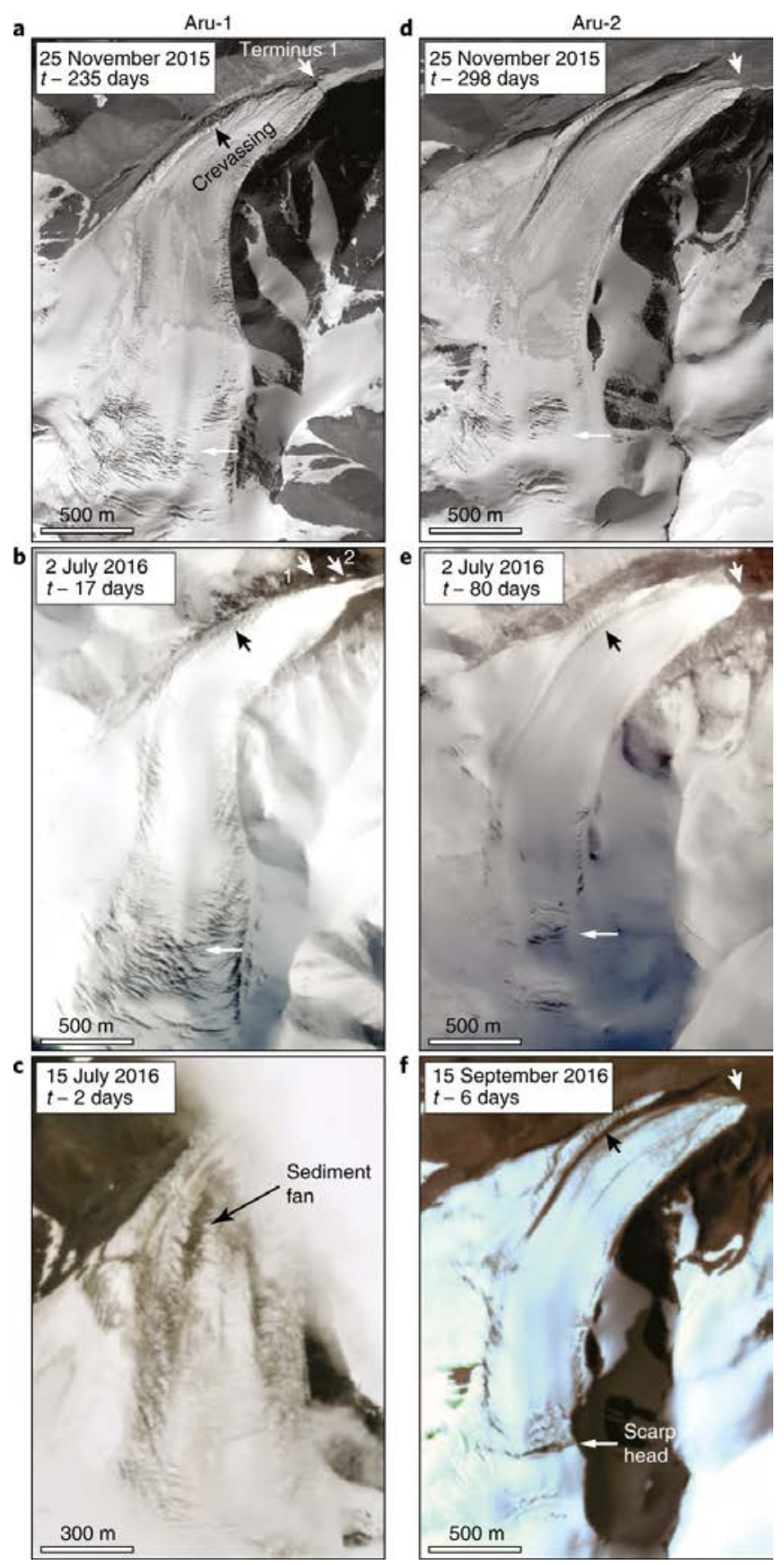

Figure 3: Satellite images over the Aru glaciers before collapse.

a, Aru-1 glacier (WorldView). Time ' $\mathrm{t}$ ' refers to collapse date. Glacier front position is indicated by arrow 1 . Note the particular crevassing at the northern curve of the glacier. $\mathbf{b}$, Aru-1 (Planet). The glacier front was at arrow 2. c, Aru-1 (Planet). A sediment fan on the glacier surface two days before collapse originated from a crevasse. Panel $c$ is slightly zoomed in. d, Aru-2 (WorldView). e, Aru-2 (Planet). f, Aru-2 (Planet), six days before collapse. The horizontal arrow indicates the scarp head positions of the later detachments. 

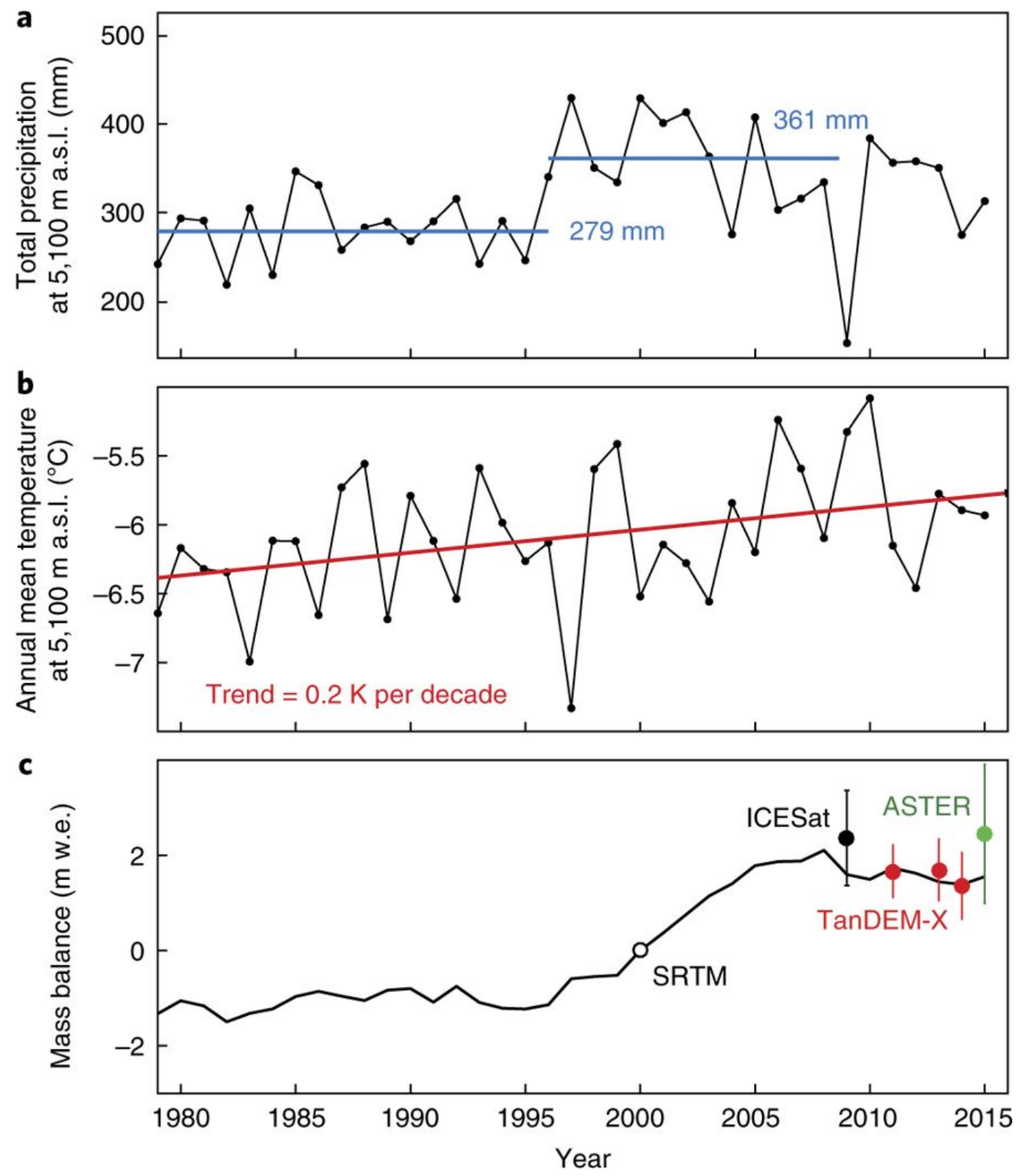

Figure 4: Climatic data series and modelled mass-balance of the Aru glaciers.

a, Precipitation over the Aru Range from ERA interim reanalysis, suggesting a distinct increase at around 1995. Bold lines are averages 1979-1995 and 1995-2008. b, Air temperature over the

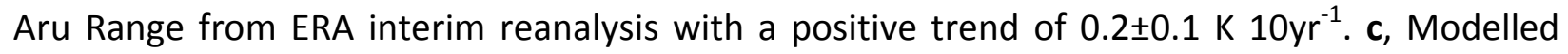
cumulative glacier water equivalent (w.e.) mass balance of the Aru glaciers, driven by ERA interim reanalysis. Model relative to the year 2000 (SRTM DEM), and parameters tuned using geodetic mass balances (ICESat, 2003-2008; SRTM-X vs. TanDEM-X, 2000-2011/2013/2014; ASTER, 2000-2015, end points indicated). 

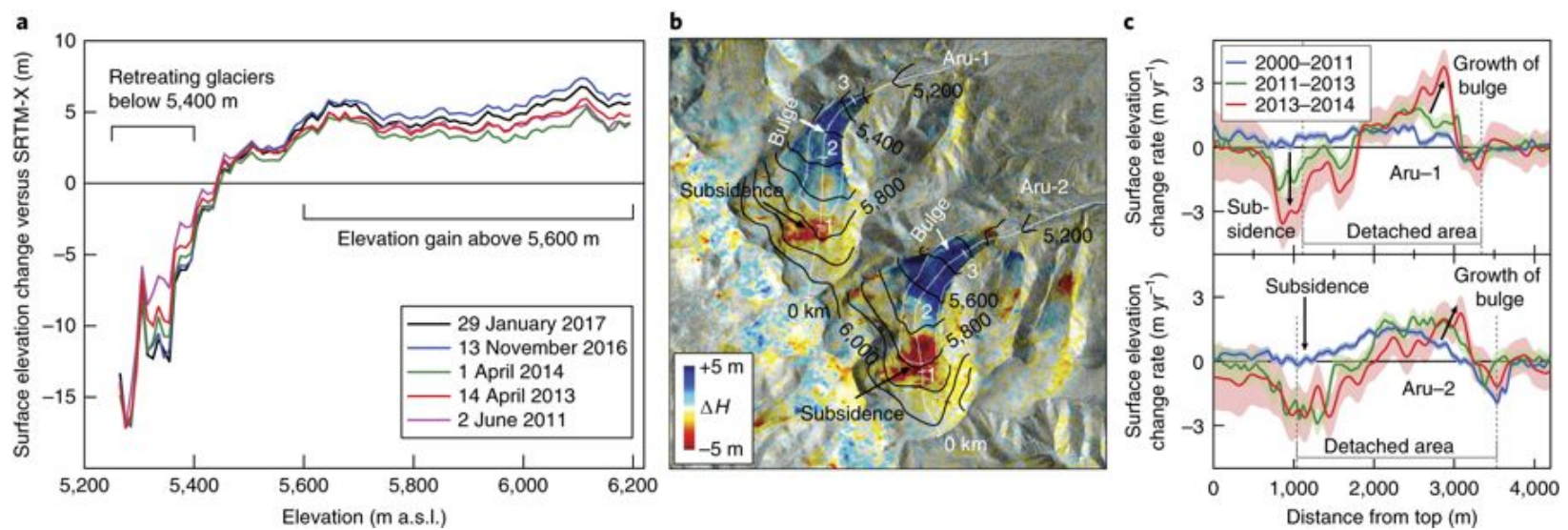

Figure 5: Glacier thickness changes over the Aru region and Aru glaciers since 2000.

a, Glacier surface elevation changes between SRTM-X (2000) and various TanDEM-X DEM dates over non-surging glaciers plotted against elevation. $\mathbf{b}$, TanDEM-X derived surface elevation change map between June 2011 and April 2013. c, SRTM-X and TanDEM-X surface elevation change rates over Aru glacier profiles (in panel b) showing bulging and bulge propagation over the period 2000-2014. Simultaneous bulge growth and frontal thinning/retreat steepens the glacier front. Line shading indicates one standard deviation uncertainty. 


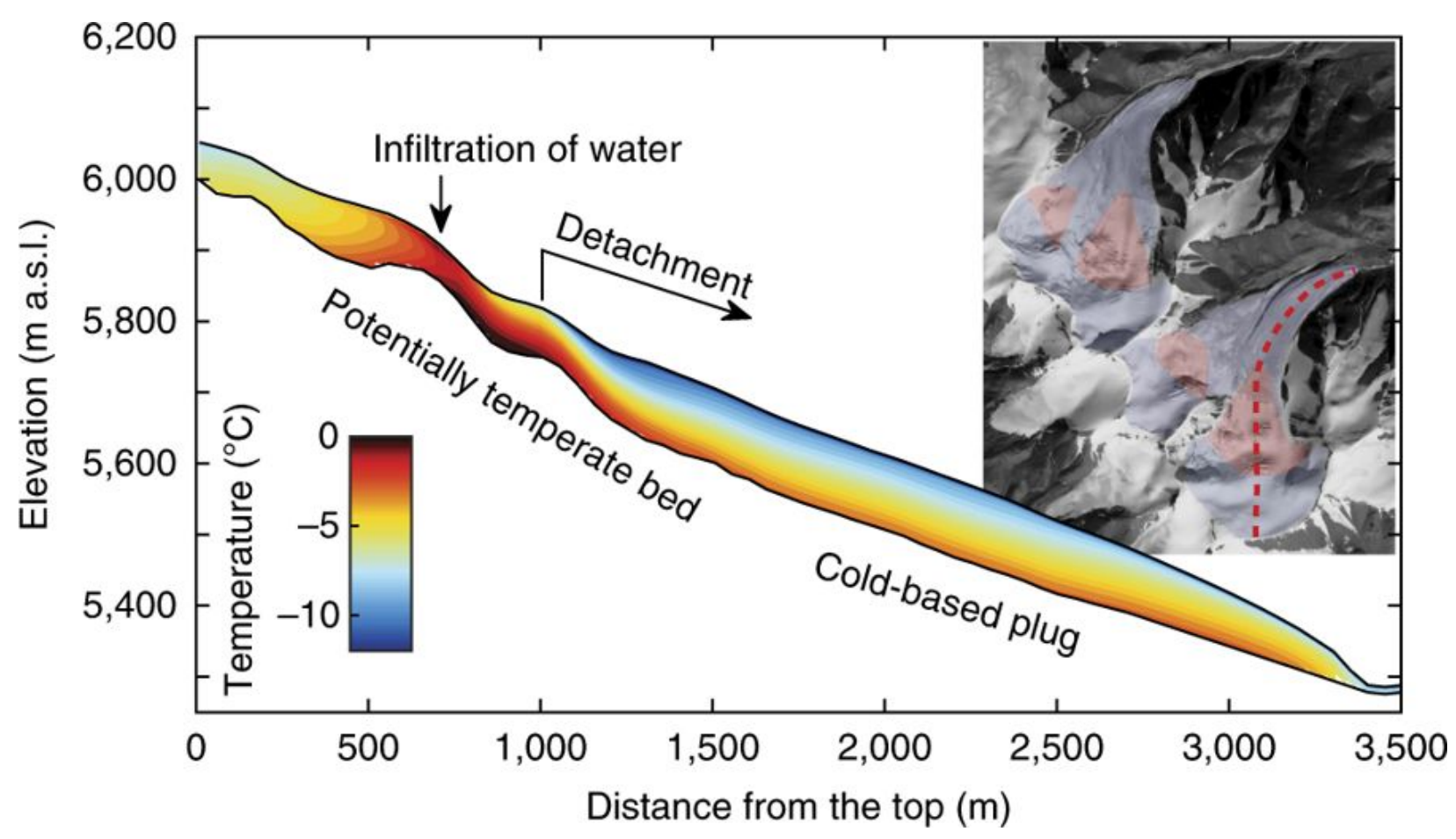

Figure 6: Modelled two-dimensional thermal structure of the Aru glaciers.

a, Median scenario of a suite of thermodynamic steady-state flow-line modelling results of the thermal structure of Aru-2 for the mean 1980-1995 climate conditions. The models indicate temperate (thawed) basal conditions at the position of the later scarp head and under the upper zone of the detached glacier part, else cold (frozen) basal conditions. Results for Aru-1 are very similar and not shown. b, Schematic representation of the basal temperature of the Aru glaciers at steady state. Areas in blue are likely cold-based ice; areas in red are potentially temperate-based ice. 


\section{Methods}

\section{Satellite remote sensing}

Satellite data are critical to our understanding of the two Aru glacier collapses. Images from the Corona cold-war era spy satellite programme over the period 1961-1980 are orthorectified using a rational function sensor model, and orthoimages and DEMs from 2015 WorldView and SPOT7 high-resolution optical satellite stereo data as reference ${ }^{51}$ (Supplementary Information S1). Sensor-model residuals range over 8.6-15.2m RMS horizontally, for the different images respectively, but lateral offsets might be larger on glaciers where elevations changed significantly between acquisition dates and the DEMs, causing orthorectification offsets.

Satellite images of 1990-2017 from the Landsat 4-8 series, and Sentinel-2 data of 2016 are provided georeferenced and terrain corrected. 24-days repeat-pass Sentinel-1 radar images of 2014 until 2016 were geocoded using the ESA Sentinel tool box SNAP. The Planet cubesat constellation $^{52}$ consists of $\sim 150-200$ free-flying micro-satellites that carry RGB+NIR frame cameras that image the Earth surface in nadir direction with resolutions of $2-4 \mathrm{~m}^{53}$. Even if not yet complete in 2016, the Planet cubesat constellation covered the Aru area 180 times in 2016 with completely or partially cloud-free images. The data used here are provided georeferenced and orthorectified.

DEMs from 2011 ALOS PRISM, 2015 WorldView and SPOT7, and 2016 Pleiades optical satellite stereo data are obtained from parallax matching using standard routines within the AMES Stereo Pipeline software ${ }^{54}$ and $\mathrm{PCl}$ Geomatica $^{55}$. For georeferencing we use the orbital information provided but co-register the respective DEMs before computing DEM differences ${ }^{56,57}$. For stable ground we obtain vertical differences between the 2015 WorldView and SPOT7 DEMs of $\sim 2 \mathrm{~m}$ RMS. An assessment ${ }^{58}$ of Pleiades DEMs over various mountain glaciers gave accuracies of better than $\pm 1 \mathrm{~m}$, and $\pm 1.3 \mathrm{~m}$ for elevation differences between a Pleiades and SPOT5 DEM. We consider thus an accuracy of about $\pm 2 \mathrm{~m}$ for individual pixels of our DEM differences to be conservative. Using an equally conservative distance of spatial error auto-correlation $^{59}$ of $400 \mathrm{~m}$ we obtain thus standard errors of around $\pm 0.8 \mathrm{~m}$ and $\pm 0.9 \mathrm{Mm}^{3}$ for the elevation change and volume change of the collapse source areas, respectively, and around $\pm 0.1 \mathrm{~m}$ and $\pm 0.8 \mathrm{Mm}^{3}$ for the avalanche deposits.

Monoscopic WorldView data of 2011 and 2013 are orthorectified using the 2015 Worldview DEM. Elevation differences between 2015 and 2011/2013 will lead to lateral orthorectification errors of only a few metres and have thus no significant impact on our results.

An estimate of glacier volume change rate is obtained from a time series of ASTER DEMs (Supplementary Information S7) following methods presented and validated earlier ${ }^{29,60}$. We generate 48 DEMs from ASTER AST_L1A images acquired between October 2000 and April 2015 using the Ames Stereo Pipeline ${ }^{54}$. All ASTER DEMs are corrected for planimetric and altimetric 
shifts and higher-order biases are corrected ${ }^{29}$. For each $30 \mathrm{~m}$ DEM-pixel, we fit linear trends through the ASTER elevation values iteratively excluding outliers ${ }^{29}$.

Based on bistatic TanDEM-X SAR data of 2011, 2013, 2014, and 2016, DEMs are produced using standard interferometric techniques (SLC stack coregistration, interferogram formation, topographic phase removal based on the SRTM, phase unwrapping using the software SNAPHU, re-addition of SRTM-derived topographic phase, phase to height conversion and geocoding). Absolute height calibration is done using GPS field measurements. Linear trends in DEM differences and undulations $(<5 \mathrm{~m})$ contained in differences to the SRTM (February 2000) are corrected by spatial extrapolation of height corrections estimated from stable terrain with low topography. Erroneous DEM values are removed for low interferometric coherence (TanDEM-X) and for height differences larger $>10 \mathrm{~m}$ between the simultaneously acquired $X$ - and C-band SRTM.

To minimize effects of radar penetration, we do not use the C-band SRTM DEM but rather the $X$-band SRTM that covers the Aru range. The penetration of X-band radar waves is smaller than the one of C-band waves, and especially for differences between the TanDEM-X and SRTM-X DEMs, penetration effects minimize when acquired under similar ground conditions. For such conditions we estimate a maximum penetration depth difference of $1 \mathrm{~m}$ based on a conservative guess of $30 \%$ of the upper bound of $3 \mathrm{~m}$ penetration depth difference determined for a dry and a wet snow TanDEM-X DEM acquired in June and July 2011. Based on previous studies $^{61}$, tests on stable ground, and including above penetration uncertainty we estimate a total accuracy for individual DEM differences of $\pm 2.6 \mathrm{~m}$ for SRTM/TanDEM-X and $\pm 1.5 \mathrm{~m}$ for TanDEM-X alone.

The inundation by the Aru-1 lake impact wave was estimated from interferometric coherence loss within a pre/post-event Sentinel-1 image pair, from inspection of pre/post-event optical high-resolution images, and confirmed by GPS field survey. For interferometric change detection analysis, Sentinel-1 SLC data are processed using the tool box SNAP. For other visual analyses, GRD-format SAR data from Sentinel-1 are orthorectified based on the SRTM-C DEM using PCl Geomatica and Google Earth Engine.

\section{Event volumes}

The volume estimates for the twin collapses are based on differencing DEMs from before (SRTM, TanDEM-X, ALOS PRISM World DEM, WorldView stereo and SPOT7 stereo) and after the events (Pleiades, TanDEM-X). We differentiate between the collapse volumes (i.e., the volume of the detached glacier parts) and the avalanche volumes (i.e., the deposited volumes).

The raw DEM differences were corrected for (i) the ice flux into the detached section of the glaciers that happened between detachment date and DEM date, for (ii) secondary smaller avalanches, and (iii) melt of the ice deposits on land and in the Aru Co lake (for Aru-1), and involved also (iv) density scenarios for the deposits (Supplementary Information S2). 
From our above DEM accuracies we conservatively estimate an uncertainty of the collapse volumes of $\pm 0.8-0.9 \mathrm{Mm}^{3}$, while the small deviations between the DEM differences from the different before/after DEM combinations possible suggest an even higher accuracy. Further uncertainty stems from the above corrections of elevation changes between the detachment date and the date of Pleiades stereo acquisition (1 October 2016), in particular from partial closure of the detachment depression due to ice flux from the upper glacier parts and secondary avalanching or ice-debris erosion. We estimate the volume involved in these processes to amount up to $3 \mathrm{Mm}^{3}$ and attach a $\pm 1 \mathrm{Mm}^{3}$ uncertainty to this number (Supplementary Information S2). Conservatively adding up the uncertainties from the DEMs and the volume changes after detachment, instead of using root-sum-square (RSS) error propagation, leads to a total volume uncertainty for the collapses of roughly $\pm 2 \mathrm{Mm}^{3}$.

Reconciling the collapse volumes and the deposited avalanche volumes, the latter also obtained from DEM differencing, requires or provides, respectively, estimates for subaerial and aqueous melt (Aru-1), and deposit densities (Aru-1 and 2).

Based on the short time difference of ten days between the Aru-2 collapse and the Pleiades stereo acquisition, and air temperatures of around freezing suggested by ERA-interim data and snow fall in the region (from optical satellite data), we neglect melt of the Aru-2 deposits over these ten days. To roughly estimate the subaerial melt for the Aru-1 deposits between collapse and acquisition of the Pleiades data, we use a simple positive-degree day (PDD) approach based on meteorological and reanalysis data, neglect snow accumulation, and assume a range of PDD factors ${ }^{62,63}$ comprised between $7.010^{-3}$ and $12.010^{-3} \mathrm{~m}$ w.e. $\mathrm{K}^{-1} \mathrm{~d}^{-1}$ (Supplementary Information $\mathrm{S} 3,5)$. The melt rates obtained agree with glaciological studies in central Tibet ${ }^{64,65}$. In further agreement, repeat GPS measurements over some points on the Aru-1 deposits between 13 August and 24 October 2016 suggest elevation loss of around $2.8 \mathrm{~m}$.

DEM differencing over the Aru-2 deposits gives an avalanche volume of $102 \mathrm{Mm}^{3}$. Neglecting the evacuation of collapse and avalanche water content and sediment entrainment, and assuming the density difference between the detached $\left(900 \mathrm{~kg} \mathrm{~m}^{-3}\right.$ ice density) and deposited volume to be the only factor contributing to the volume differences, suggests a mean deposit density of $750 \mathrm{~kg} \mathrm{~m}^{-3}$, which seems reasonable for the ice melange deposited (Supplementary Information S2).

The Aru-1 deposits had a volume of $33-36 \mathrm{Mm}^{3}$ on 1 October 2016 . Correction of this volume for aqueous melt in Aru Co $\left(5.5 \mathrm{Mm}^{3}\right)$, a density scenario of $750 \mathrm{~kg} \mathrm{~m}^{-3}$ as indicated for the Aru-2 collapse, and a rough $3 \mathrm{~m}$ w.e. melt scenario between 17 July and 1 October 2016, reconstructs for instance a collapse volume of around $72 \mathrm{Mm}^{3}$, i.e., very close to the measured source volume of around $68 \mathrm{Mm}^{3}$ (Supplementary Information S2).

\section{Climate and mass-balance calculations}

We compare daily climate data from reanalysis and regional meteorological stations to estimate the climate in the Aru range since 1970. These data are used to model mass balance of the Aru glaciers based on a PDD model approach ${ }^{66}$ that uses two distinct PDD factors for ice and 
snow, and takes into account the albedo feedback linked to precipitation increase. Downscaling of climate data to glacier scale is done assuming a constant lapse rate for temperature and precipitation. Furthermore, we apply a multiplicative factor to precipitation in order to correct a very likely bias in the precipitation ${ }^{67}$. We tune the model parameters to fit to mass balance as reconstructed from geodetic data (ICESat, TanDEM-X and ASTER) using a Bayesian probabilistic approach where the probability-density function is calculated by exploring the whole parameters space (Supplementary Information S3). From this procedure, we conclude that the ERA-interim reanalysis climate is able to explain the geodetic mass balance observations in the Aru range sufficiently, mainly due to a precipitation increase since around 1995.

\section{Thermal structure of the glaciers}

The thermal structure of the Aru glaciers is simulated using a 2D flow-line of the southern Aru-2 glacier as an example (Aru-1 turns out to have a very similar structure). The bedrock topography is reconstructed based on the post-event Pleiades DEM for the detached lower part, and using surface slope and a simple "plastic approximation" ${ }^{37}$ for the upper part, which has not collapsed. The model follows a published approach ${ }^{68}$, solves the coupled Stokes and enthalpy equations, and takes into account melt-water percolation and refreezing in the firn and snow. The free surface equation is used to compute geometrical change of the glacier surface by mesh deformation. Boundary conditions are determined by basal heat flux, surface temperature, surface melting, and surface mass balance. The model is numerically solved by the finite element software Elmer/Ice. The firn density is computed from the firn thickness given by the mass-balance model and assuming a linear density increase from the surface to the ice. We run the model using a constant climate until it reaches a steady state glacier. We apply a variety of parameter sets in order to evaluate the range of possible thermal regimes for the model glacier (Supplementary Information S9).

\section{Seismic activity and analysis}

We used the USGS earthquake catalogue to investigate whether significant ground motion from local earthquakes could have triggered the collapses of Aru-1 or Aru-2. Previous studies suggest that significant slope instability such as landslides may be triggered when peak ground acceleration exceeds a certain threshold, which was proposed ${ }^{69}$ to be on the order of $1 \mathrm{~m} \mathrm{~s}^{-2}$. Considering that this threshold value also applies to a glacier collapse, significant glacier destabilization would require a local $(<10 \mathrm{~km}$ distance) earthquake with magnitude equal or larger than 4 , a distant $(<100 \mathrm{~km})$ earthquake with magnitude equal or larger than 6 or a very distant $(<1000 \mathrm{~km})$ earthquake with magnitude equal or larger than eight ${ }^{70}$. Within months prior to the Aru glaciers collapse, there were no magnitude $>8$ earthquakes observed within $1000 \mathrm{~km}$ from the Aru glacier site, as well as no magnitude $>6$ and $>4$ within 100 and $10 \mathrm{~km}$, respectively (Supplementary Information S10). Over the past 7 years, seismicity within $100 \mathrm{~km}$ from the Aru glaciers has been limited to about a dozen of magnitude 4-5 earthquakes, none of which particularly close in time to the Aru collapses. The most significant peak acceleration values prior to the collapses were due to a magnitude 4.1 earthquake that occurred at $10 \mathrm{~km}$ distance 
on 16 December 2015, 6 months prior to the Aru-1 collapse and 5 months after Aru-1 started advancing. Thus, it is very unlikely that either of the collapses were triggered by earthquakes.

The avalanche-induced seismic waves and our seismic source inversions based on them are outlined in the Supplementary Information S10.

\section{Geothermal activity}

The local population in the Aru region mentions the existence of warm springs $15 \mathrm{~km}$ north of the Aru glaciers. We consulted a number of ASTER and Landsat thermal imagery of all seasons but were unable to detect any clear indication of abnormal geothermal surface heat flux close to the glaciers, in the detachment zone, or anywhere near the area. However, the combination of low spatial resolution of the thermal bands used $(60-90 \mathrm{~m})$ with the rough topography and variable snow and ice cover would make such detection of small surface heat-flux anomalies uncertain. Also inspection of high-resolution satellite images over the exposed glacier bed gives no conclusive indications about potential sources of significantly increased geothermal heat flux. We identify, though, some spots around the glaciers that could be examined closer in the field with respect to abnormal geothermal heat flux, such as a hollow in the ice at one place at the margin of the Aru-2 glacier, however not in proximity to the detached glacier part. Strongly reduced backscatter between repeat TerraSAR-X data over winter 2016/2017 indicates some small outflows of liquid water in the avalanche zone despite of freezing conditions.

\section{Lithology}

Non-public geological maps of the Aru region were made available for inspection. They indicate a dominance in the Aru Range of un-metamorphosed or lightly metamorphosed fine-grained Permian sedimentary rocks, especially sandstone, siltstone, slate, and conglomerate; some nearby glacierized ranges contain similar lithologies, but all other glacierized ranges also contain lithologies not present in the Aru Range, including metamorphosed schist and phyllite equivalents of rocks already mentioned, plus limestone, dolomite, massive conglomerate, and biotite granite. The fine-grained sedimentary rocks are confirmed for the avalanche zones during a field visit in July 2017 (Supplementary Information S12).

To better constrain spatial patterns of surface lithological variations we employ a 10 September 2015 cloud- and snow-free pre-avalanche Landsat 8 OLI surface reflectance image ${ }^{71}$. Cells containing significant vegetation, water, or snow are identified and masked out, and the remaining cells represent mostly rock and sediment. Thirty alluvial deposit areas-of-interest are defined from the Aru and adjacent ranges, each emanating from a discrete glacier terminus (Supplementary Information S12). Care is taken to avoid lithologic cross-sampling from sediment feeding from adjacent glacier systems that intersect the targeted alluvium. Surface reflectance and selected band ratios are tabulated for OLI bands 1-7 pixels in each of the thirty glacier-fed alluvial deposits. These band $\operatorname{ratios}^{72,73}$ are used here to identify spectral clusters that may pertain to distinct lithologies. 


\section{Uncertainties}

Our measurements and data include a range of uncertainties as summarized in the following. Precipitation data: the exact precipitation over the Aru glaciers is uncertain but meteorological stations, GPM IMERG data, and local reports agree about the particularly high precipitation rates in 2016 and several previous years. Similarly, while yearly rates of precipitation change

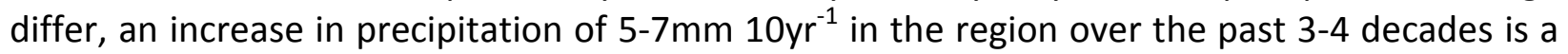
robust finding across the datasets and furthermore supported by analyses of the pronounced growth of endorheic lakes ${ }^{34,74,75}$.

Uncertainties in glacier length, elevation and volume changes, glacier surface velocities, and Aru lake impact wave run-up are low and well understood from consistent results from multiple independent measurements and from published method validations. Glacier length errors range within $1-60 \mathrm{~m}$ depending on sensor used, elevation within \pm 1 to $\pm 5 \mathrm{~m}$ (TanDEM-X and SRTM, respectively), glacier surface velocities within $\pm 0.01-0.05 \mathrm{~m} \mathrm{~d}^{-1}$ (WorldView and Sentinel2 ), and wave run-up within $\pm 20 \mathrm{~m}$ horizontally (Sentinel-1; better for Planet and GPS).

Avalanche speed and characteristics: the high avalanche speeds are confirmed by both local reports and seismic data. High initial avalanche water content is corroborated by high precipitation and, in particular, melt rates found weeks before the events by observations in radar and optical satellite images.

Thermal and soft-bed glacier conditions: The existence of cold-based glacier fronts and margins are supported by thermal modelling using a wide range of plausible parameter sets, and by the geographic setting of the study area in a permafrost region ${ }^{35,76}$. The main uncertainty remains in the existence of basal temperate ice in the accumulation area. The unbalanced mass transfer observed from surface height change suggests the presence of temperate basal ice at least after 2010. The presence of fine-grained glacier beds is confirmed by a specific field visit in July 2017, which revealed large amounts of silt/clay in the upper avalanche path of Aru-1. Such soils are known to have a strong impact on the motion of glaciers ${ }^{38-40}$ and on landsliding ${ }^{41}$.

Overall, our main conclusions remain robust against the identified and quantified uncertainties. Rather than a single factor, a rare transient array of factors combined to both increase shear stress and reduce shear strength, eventually resulting in failure. The relative importance of these factors can hardly be quantified which is a common conclusion in other slope failure studies in high mountains ${ }^{77,78}$, and in particular a natural consequence of the rareness of the events studied here. The uniqueness of the events is confirmed by (i) the dense satellite data time-series, which does not indicate similar collapses in the Aru range and the range north of it since 1961, and since 1972 for the whole western Tibetan Plateau, and (ii) testimonies of local herders who do not recall any similar event. 


\section{Data availability}

Publicly available remote sensing data sources used in this study include Sentinel- 1 and 2 available from https://scihub.copernicus.eu/, Landsat, SRTM-C and Corona, available from http://earthexplorer.usgs.gov, ASTER, available from https://reverb.echo.nasa.gov/, SRTM-X from http://eoweb.dlr.de, GPM IMERG, available from https://pmm.nasa.gov/. Pleiades data are commercial but academic access exists through ISIS (http://www.isis-cnes.fr/). WorldView data are commercial. Planet data are commercial but academic access schemes exist (https://www.planet.com/products/education-and-research/). TerraSAR-X and TanDEM-X data are available via http://eoweb.dlr.de free of charge via scientific proposals. Seismic records are publicly available from http://www.iris.edu, and earthquake data from https://earthquake.usgs.gov/.

\section{Code availability}

The image correlation code CIAS is available from http://mn.uio.no/icemass. The AMES stereopipeline code is available from https://ti.arc.nasa.gov/tech/asr/intelligent-robotics/ngt/stereo/. The SNAP remote-sensing toolbox can be downloaded from http://step.esa.int/, and Elmer/Ice from http://elmerice.elmerfem.org/.

\section{References}

1 Faillettaz, J., Funk, M. \& Vincent, C. Avalanching glacier instabilities: Review on processes and early warning perspectives. Rev Geophys 53, 203-224 (2015).

2 Huggel, C. Recent extreme slope failures in glacial environments: effects of thermal perturbation. Quaternary Sci Rev 28, 1119-1130 (2009).

3 Evans, S. G. et al. A re-examination of the mechanism and human impact of catastrophic mass flows originating on Nevado Huascaran, Cordillera Blanca, Peru in 1962 and 1970. Eng Geol 108, 96-118 (2009).

4 Evans, S. G. \& Delaney, K. B. in Snow and Ice-related Hazards, Risks, and Disasters Hazards and Disasaters Series (eds W. Haeberli \& C. Whitemann) 563-606 (Elsevier, 2015).

5 van der Woerd, J. et al. Giant, similar to M8 earthquake-triggered ice avalanches in the eastern Kunlun Shan, northern Tibet: Characteristics, nature and dynamics. Geol Soc Am Bull 116, 394406 (2004).

6 Harrison, W. D. \& Post, A. S. How much do we really know about glacier surging? Ann Glaciol 36, 1-6 (2003).

7 Yasuda, T. \& Furuya, M. Dynamics of surge-type glaciers in West Kunlun Shan, Northwestern Tibet. J Geophys Res-Earth 120, 2393-2405 (2015).

8 Harrison, W. D. et al. in Snow and Ice-related Hazards, Risks, and Disasters Hazards and Disasaters Series (eds W. Haeberli \& C. Whitemann) 437-485 (Elsevier, 2015).

9 Sevestre, H. \& Benn, D. I. Climatic and geometric controls on the global distribution of surgetype glaciers: implications for a unifying model of surging. J Glaciol 61, 646-662 (2015).

10 Murray, T., Strozzi, T., Luckman, A., Jiskoot, H. \& Christakos, P. Is there a single surge mechanism? Contrasts in dynamics between glacier surges in Svalbard and other regions. J Geophys Res-Solid 108, Artn 2237 (2003). 
11 Jiskoot, H. in Encyclopedia of Snow, Ice and Glaciers (eds V.P. Singh \& U. K. Haritashya) 415-428 (Springer, 2011).

12 Fowler, A. C., Murray, T. \& Ng, F. S. L. Thermally controlled glacier surging. J Glaciol 47, 527-538 (2001).

13 Sevestre, H., Benn, D. I., Hulton, N. R. J. \& Baelum, K. Thermal structure of Svalbard glaciers and implications for thermal switch models of glacier surging. J Geophys Res-Earth 120, 2220-2236 (2015).

14 Frappe, T. P. \& Clarke, G. K. C. Slow surge of Trapridge Glacier, Yukon territory, Canada. J Geophys Res-Earth 112, Artn F03s32 (2007).

15 Kamb, B. Glacier surge mechanism based on linked cavity configuration of the basal water conduit system. J Geophys Res-Solid 92, 9083-9100 (1987).

16 Truffer, M., Harrison, W. D. \& Echelmeyer, K. A. Glacier motion dominated by processes deep in underlying till. J Glaciol 46, 213-221 (2000).

17 Clarke, G. K. C., Collins, S. G. \& Thompson, D. E. Flow, thermal structure, and subglacial conditions of a surge-type glacier. Can J Earth Sci 21, 232-240 (1984).

18 Evans, S. G. et al. Catastrophic detachment and high-velocity long-runout flow of Kolka Glacier, Caucasus Mountains, Russia in 2002. Geomorphology 105, 314-321 (2009).

19 Huggel, C. et al. The 2002 rock/ice avalanche at Kolka/Karmadon, Russian Caucasus: assessment of extraordinary avalanche formation and mobility, and application of QuickBird satellite imagery. Nat Hazard Earth Sys 5, 173-187 (2005).

20 Haeberli, W. et al. The Kolka-Karmadon rock/ice slide of 20 September 2002: an extraordinary event of historical dimensions in North Ossetia, Russian Caucasus. J Glaciol 50, 533-546 (2004). Tian, L. D. et al. Two glaciers collapse in western Tibet. J Glaciol 63, 194-197 (2017). Heim, A. Bergsturz und Menschenleben. (Fretz und Wasmuth, Zurich, 1932). Chao, W. A. et al. Seismology-based early identification of dam-formation landquake events. Sci Rep-Uk 6, Artn 19259 (2016).

24 Christen, M., Kowalski, J. \& Bartelt, P. RAMMS: Numerical simulation of dense snow avalanches in three-dimensional terrain. Cold Reg Sci Technol 63, 1-14 (2010).

25 Hungr, O. \& McDougall, S. Two numerical models for landslide dynamic analysis. Comput GeosciUk 35, 978-992 (2009).

26 Schneider, D., Huggel, C., Haeberli, W. \& Kaitna, R. Unraveling driving factors for large rock-ice avalanche mobility. Earth Surf Proc Land 36, 1948-1966 (2011).

27 Yao, T. D. et al. Different glacier status with atmospheric circulations in Tibetan Plateau and surroundings. Nat Clim Change 2, 663-667 (2012).

28 Ye, Q. H. et al. Glacier changes on the Tibetan Plateau derived from Landsat imagery: mid1970s-2000-13. J Glaciol 63, 273-287 (2017).

29 Brun, F., Berthier, E., Wagnon, P., Kaab, A. \& Treichler, D. A spatially resolved estimate of High Mountain Asia glacier mass balances from 2000 to 2016. Nature Geosci 10, 668-673 (2017).

30 Kääb, A., Treichler, D., Nuth, C. \& Berthier, E. Brief Communication: Contending estimates of 2003-2008 glacier mass balance over the Pamir-Karakoram-Himalaya. Cryosphere 9, 557-564 (2015).

31 Berthier, E., Schiefer, E., Clarke, G. K. C., Menounos, B. \& Remy, F. Contribution of Alaskan glaciers to sea-level rise derived from satellite imagery. Nat Geosci 3, 92-95 (2010).

32 Tao, H., Borth, H., Fraedrich, K., Su, B. D. \& Zhu, X. H. Drought and wetness variability in the Tarim River Basin and connection to large-scale atmospheric circulation. Int J Climato/ 34, 26782684 (2014). 
Kapnick, S. B., Delworth, T. L., Ashfaq, M., Malyshev, S. \& Milly, P. C. D. Snowfall less sensitive to warming in Karakoram than in Himalayas due to a unique seasonal cycle. Nat Geosci 7, 834-840 (2014).

34 Zhang, G. et al. Lake volume and groundwater storage variations in Tibetan Plateau's endorheic basin. Geophys Res Lett 44, 5550-5560 (2017).

35 Gruber, S. Derivation and analysis of a high-resolution estimate of global permafrost zonation. Cryosphere 6, 221-233 (2012).

36 Boulton, G. S. \& Jones, A. S. Stability of temperate ice caps and ice sheets resting on beds of deformable sediment. J. Glacio 24, 29-43 (1979).

37 Cuffey, K. \& Paterson, W. S. B. The physics of glaciers. 4th ed., (Butterworth-Heinemann, 2010).

38 Kamb, B. Rheological nonlinearity and flow instability in the deforming bed mechanism of ice stream motion. J Geophys Res-Sol Ea 96, 16585-16595 (1991).

39 Tulaczyk, S., Kamb, W. B. \& Engelhardt, H. F. Basal mechanics of Ice Stream B, West Antarctica 1. Till mechanics. J Geophys Res-Sol Ea 105, 463-481 (2000).

40 Iverson, N. R., Hooyer, T. S. \& Baker, R. W. Ring-shear studies of till deformation: Coulombplastic behavior and distributed strain in glacier beds. J Glaciol 44, 634-642 (1998).

41 Roering, J. J. et al. Beyond the angle of repose: A review and synthesis of landslide processes in response to rapid uplift, Eel River, Northern California. Geomorphology 236, 109-131 (2015).

42 Dunse, T. et al. Glacier-surge mechanisms promoted by a hydro-thermodynamic feedback to summer melt. Cryosphere 9, 197-215 (2015).

43 Fountain, A. G., Jacobel, R. W., Schlichting, R. \& Jansson, P. Fractures as the main pathways of water flow in temperate glaciers. Nature 433, 618-621 (2005).

44 Drobyshev, V. N. Glacial catastrophe of 20 September 2002 in North Osetia. Russian Jo. Earth Sci, ES4004 (2006).

45 Chernomorets, S. S. et al. in Debris-Flow Hazards Mitigation: Mechanics, Prediction, and Assessment (eds C. L. Chen \& J. J. Major) (Millpress, 2007).

46 Zhang, W. Identification of glaciers with surge characteristics on the Tibetan Plateau. Ann Glaciol 16, 168-172 (1992).

47 Ugalde, F., Casassa, G., Marangunic, C., Mujica, R. \& Peralta, C. in XiV Congresso Geologico Chileno.

48 Heybrock, W. Earthquakes as a cause of glacier avalanches in the Caucasus. Geogr Rev 25, 423430 (1935).

49 Espizua, L. E. Fluctuations of the Rio-Del-Plomo glaciers. Geogr Ann A 68, 317-327 (1986).

50 Milana, J. P. A model of the Glaciar Horcones Inferior surge, Aconcagua region, Argentina. J Glaciol 53, 565-572 (2007).

51 Sorg, A., Kääb, A., Roesch, A., Bigler, C. \& Stoffel, M. Contrasting responses of Central Asian rock glaciers to global warming. Sci Rep-Uk 5, Artn 8228 (2015).

52 Kääb, A., Altena, B. \& Mascaro, J. Coseismic displacements of the 14 November $2016 \mathrm{Mw} 7.8$ Kaikoura, New Zealand, earthquake using the Planet optical cubesat constellation. Nat Hazard Earth Sys 17, 627-639 (2017).

53 Planet Team. Planet Data Application. Program Interface: In Space for Life on Earth. San Francisco, CA. https//api.planet.com/and https//www.planet.com/. last visited 17.11.2017., 2016).

54 Shean, D. E. et al. An automated, open-source pipeline for mass production of digital elevation models (DEMs) from very-high-resolution commercial stereo satellite imagery. Isprs J Photogramm 116, 101-117 (2016).

55 Kronenberg, M. et al. Mass-balance reconstruction for Glacier No. 354, Tien Shan, from 2003 to 2014. Ann Glaciol 57, 92-102 (2016). 
Nuth, C. \& Kääb, A. Co-registration and bias corrections of satellite elevation data sets for quantifying glacier thickness change. Cryosphere 5, 271-290 (2011).

57 Berthier, E. et al. Remote sensing estimates of glacier mass balances in the Himachal Pradesh (Western Himalaya, India). Remote Sens Environ 108, 327-338 (2007).

58 Berthier, E. et al. Glacier topography and elevation changes derived from Pleiades sub-meter stereo images. Cryosphere 8, 2275-2291 (2014).

59 Wang, D. \& Kääb, A. Modeling glacier elevation change from DEM time series. Remote SensBasel 7, 10117-10142 (2015).

60 Berthier, E., Cabot, V., Vincent, C. \& Six, D. Decadal region-wide and glacier-wide mass balances derived from multi-temporal ASTER satellite digital elevation models. Validation over the MontBlanc area. Front Earth Sci 4, Artn 63 (2016).

61 Round, V., Leinss, S., Huss, M., Haemmig, C. \& Hajnsek, I. Surge dynamics and lake outbursts of Kyagar Glacier, Karakoram. Cryosphere 11, 723-739 (2017).

62 Kayastha, R. B. et al. Positive degree-day factors for ice ablation on four glaciers in the Nepalese Himalayas and Qinghai-Tibetan Plateau. Bulletin of Glaciological Research 20, 7-14 (2003).

63 Gao, H. K., He, X. B., Ye, B. S. \& Pu, J. C. Modeling the runoff and glacier mass balance in a small watershed on the Central Tibetan Plateau, China, from 1955 to 2008. Hydrol Process 26, 15931603 (2012).

64 Mölg, T., Maussion, F., Yang, W. \& Scherer, D. The footprint of Asian monsoon dynamics in the mass and energy balance of a Tibetan glacier. Cryosphere 6, 1445-1461 (2012).

65 Caidong, C. D. \& Sorteberg, A. Modelled mass balance of Xibu glacier, Tibetan Plateau: sensitivity to climate change. J Glaciol 56, 235-248 (2010).

66 Gilbert, A. et al. Sensitivity of Barnes Ice Cap, Baffin Island, Canada, to climate state and internal dynamics. J Geophys Res-Earth 121, 1516-1539 (2016).

67 Immerzeel, W. W., Wanders, N., Lutz, A. F., Shea, J. M. \& Bierkens, M. F. P. Reconciling highaltitude precipitation in the upper Indus basin with glacier mass balances and runoff. Hydrol Earth Syst Sc 19, 4673-4687 (2015).

68 Gilbert, A., Gagliardini, O., Vincent, C. \& Wagnon, P. A 3-D thermal regime model suitable for cold accumulation zones of polythermal mountain glaciers. J Geophys Res-Earth 119, 1876-1893 (2014).

69 Wang, X., Nie, G. \& Wang, D. Relationships between ground motion parameters and landslides induced by Wenchuan earthquake. Earthq Sci 23, 233-242 (2010).

70 Liu, K. S. \& Tsai, Y. B. Attenuation relationships of peak ground acceleration and velocity for crustal earthquakes in Taiwan. B Seismol Soc Am 95, 1045-1058 (2005).

71 Vermote, E., Justice, C., Claverie, M. \& Franch, B. Preliminary analysis of the performance of the Landsat 8/OLI land surface reflectance product. Remote Sens Environ 185, 46-56 (2016).

72 Ashley, R. P. \& Abrams, M. J. Mapping of limonite, clay mineral, and alunite contents of hydrothermally altered rocks in cuprite mining district, Nevada, using aircraft scanner iagery for 0.46-2.36 mum spectral region. Econ Geol 73, 307-307 (1978).

73 Mwaniki, M. W., Matthias, M. S. \& Schellmann, G. Application of remote sensing technologies to map the structural geology of Central Region of Kenya. leee J-Stars 8, 1855-1867 (2015).

74 Song, C. Q., Huang, B. \& Ke, L. H. Heterogeneous change patterns of water level for inland lakes in High Mountain Asia derived from multi-mission satellite altimetry. Hydrol Process 29, 27692781 (2015).

75 Zhang, G. et al. Extensive and drastically different alpine lake changes on Asia's high plateaus during the past four decades. Geophys Res Lett 44, 252-260 (2017).

76 Ran, Y. H. et al. Distribution of permafrost in China: an overview of existing permafrost maps. Permafrost Periglac 23, 322-333 (2012). 
77 Fischer, L., Amann, F., Moore, J. R. \& Huggel, C. Assessment of periglacial slope stability for the 1988 Tschierva rock avalanche (Piz Morteratsch, Switzerland). Eng Geol 116, 32-43 (2010).

78 Phillips, M. et al. Rock slope failure in a recently deglaciated permafrost rock wall at Piz Kesch (Eastern Swiss Alps), February 2014. Earth Surf Proc Land 42, 426-438 (2017). 